\title{
The spatial spillover effect of High speed railway on the Beijing-Shanghai HSR economic zone
}

\author{
Gongding Wei ${ }^{1, a}$, Xuemei $\mathrm{Li}^{2, \mathrm{~b}}$ \\ ${ }^{1}$ School of Economies and Management, Beijing Jiaotong University, Beijing, China \\ 2 School of Economies and Management, Beijing Jiaotong University, Beijing, China \\ a12113102@bjtu.edu.cnmail, binter198685@163.com
}

\begin{abstract}
Keywords: High-speed rail, Spatial lag fixed effect model, Spatial spillover effect.
Abstract. Based on the 57 prefecture-level cities and three municipality (Beijing, Tianjin and Shanghai) in the Beijing-Shanghai high-speed rail economic zone over 2006-2016. We establish traditional the ordinary panel model and the spatial lag fixed model, in order to investigate the spatial spillover effect of HSR on local and regional economic growth. During this period, the spatial spillover effect of the Beijing-Shanghai high-speed rail economic zone based on the railway network not only effectively promotes the economic development of the region, but also has a significantly positive impact on the economic growth of neighboring regions. The development of urbanization does not match the economic development of Beijing-Shanghai high-speed railway economic zone. The economic zone of Beijing-Shanghai high-speed railway shows the optimization and upgrading trend from economic growth which is mainly based on the growth of secondary industry to coordinating development of secondary and tertiary industrial structure.
\end{abstract}

\section{Introduction}

By the end of 2017, the national railway business mileage reached 127 thousand kilometers. High-speed railway acts as a new and fast way of transportation, and the high-speed railway network has a huge impact on the development of China's regional economy. The research of high-speed railway impact on urban and region has been deepened and research paradigms are continuously enriched. In recent years, the research on the influence of high-speed railway on urban and regional economic development mainly follows a thread: the shortening of the travel time of high-speed railway causes the change of traffic accessibility, triggering the spatial effect, having corresponding influence on the city and the regional economy, and remolding the spatial structure and form of urban and regional economy. Scholars usually focus on the direct economic benefits of high speed railway, the impact of high-speed railway on industry, the impact of high-speed railway on the urban and regional macro-economy, and the impact of high-speed railway on the economic space of urban agglomeration. The research shows that the investment in the high speed railway is huge, and the investment in the infrastructure will directly pull the economic benefits which needs a large number of labor employment[1], accelerates the flow of capital and technology among cities along the railway, and promotes the development of the tertiary industry[2], especially for the business and trade, finance, real estate and other services[3], and form an aggregation effect and upgrades the industrial structure and accelerates the urbanization process along the railway[4]. The time-space effect caused by high-speed railway reduces the regional traffic cost, improves the location conditions, reduces the space transaction cost[5], promotes the development of regional economic integration along the railway, and boosts the appearance of the high-speed railway corridor and the economic corridor, which further improves the accessibility between the existing urban areas, and strengthens the interaction between cities and urban areas along the railway. And it also leads to the reconstruction of regional and urban space[6].

Existing research focused on the change of accessibility affected by the HSR on the macro level. The research always use the time or distance index to calculate the gap of accessibility before and after the operation of HSR[7]. There are many qualitative research on the influence of HSR on urban and regional economy. The studies on the spatial spillover effect of China's HSR are scarce. How to build 
the spatial econometric model to quantitative analysis of HSR spatial spillover effects on regional economic growth is useful for understanding the influence of HSR on the urban and regional economy. It has strong theoretical and practical significance.

In this paper, considering that current studies of Zhao[8]and Jiang[9], based on the 57 prefecture-level cities and three municipality (Beijing, Tianjin and Shanghai) in the Beijing-Shanghai high-speed rail economic zone over 2006-2016. We establish the ordinary panel model and the spatial lag fixed model, in order to investigate the spatial spillover effect of HSR on local and regional economic growth of the Beijing-Shanghai high-speed rail economic zone.

\section{Methodology and data}

\section{Spatial weight matrix}

The spatial weights matrix $\mathrm{W}$ is a $\mathrm{N} * \mathrm{~N}$ positive matrix. $t_{i j}$ is the minimum rail travel time between city $i$ and city $j$, and is mathematically formulated as follows:

$$
w_{i j}=\frac{1 / t_{i j}}{\sum_{j} 1 / t_{i j}}
$$

Economic spatial weight matrix is the gap of GDP per ten thousand person between city $i$ and city j. This spatial weight matrix is used to analysis the spatial negative spillover effect on local economic growth through the transportation infrastructure, and is mathematically formulated as follows[10]:

$$
W_{i j}=\frac{1 /\left|X_{i}-X_{j}\right|}{\sum_{j} 1 /\left|X_{i}-X_{j}\right|}
$$

section headings are in boldface capital and lowercase letters. Second level headings are typed as part of the succeeding paragraph (like the subsection heading of this paragraph).

\section{Spatial lag fixed effect model}

In this study, the spatial spillover effect on local economic growth is tested by the econometric model as follows:

$$
G D P_{i t}=\rho W G D P_{j t}+\beta_{1 t} L A B_{i t}+\beta_{2 t} I N V_{i t}+\beta_{3 t} S C_{i t}+\beta_{4 t} H L_{l t}+\beta_{5 t} U R_{i t}+\beta_{6 t} F E_{i t}+\alpha_{i t}+\varepsilon_{i t}
$$

where $i \neq j, W$ is the spatial weight matrix . $\rho$ are the coefficients of the spatial spillover effect.

\section{Data description}

The dependent variable is measured by GDP of the city in the Beijing-Shanghai high-speed railway economic zone.

The selection of control variables are described as follows: (1) Labor (LAB) is measured by the employment number of the city in the Beijing-Shanghai high-speed railway economic zone. (2) Investment (INV) is measured by the fixed assets investment of the city in the Beijing-Shanghai high-speed railway economic zone. (3) Consumption (SC) is measured by the total retail consumer goods of the city in the Beijing-Shanghai high-speed railway economic zone. (4) The optimization of the industrial structure level (HL) is measured by the ratio between the second industry and the third industry of the city in the Beijing-Shanghai high-speed railway economic zone. (5) Urbanization level (UR) is measured by the ratio between the nonagricultural population and total population of the city in the Beijing-Shanghai high-speed railway economic zone. (6) Government finance expenditure (FE) is measured by the finance expenditure of the city in the Beijing-Shanghai high-speed railway economic zone.

Considering the availability of data and the formal operation of Beijing-Shanghai high-speed rail is June 30, 2011, we choose 57 prefecture-level cities and three municipality (Beijing, Tianjin and Shanghai) in the Beijing-Shanghai high-speed rail economic zone over 2006-2016 as our research sample. The research period will divide into three period as follows: (1) No-HSR period (2006-2010); (2) HSR period (2011-2016); (3) General period (2006-2016). The relevant data of HSR are from 
China Rail Schedule released by China Railway Corporation over 2006-2016, and other data are derived from China City Statistical Yearbook, provincial statistical yearbooks, and urban statistical bulletins.

\section{Results and discussion}

\section{Spatial autocorrelation analysis}

From Table 1, we can know that the Moran Index of the numerical of GDP passed 5\% significant level test, and the Moran Index is positive. The test shows that there is a significant positive spatial correlation among the regions after 2006. The Beijing-Shanghai high-speed rail economic zone isn't a complete random station, is effected by the economic behavior of other areas in the Beijing-Shanghai high-speed rail economic zone. The LM test and Robust LM test of the spatial model passed 5\% significant level test, the Hausman test also passed $1 \%$ significant level test. So we need to test the spatial spillover effect on local economic growth through the spatial lag fixed effect model based on the economic distance.

Table 1. The Moran Index of GDP.

\begin{tabular}{cccc}
\hline Year & Moran Index & Year & Moran Index \\
\hline 2006 & 0.129 & 2012 & 0.106 \\
\hline 2007 & 0.128 & 2013 & 0.103 \\
\hline 2008 & 0.125 & 2014 & 0.098 \\
\hline 2009 & 0.120 & 2015 & 0.099 \\
\hline 2010 & 0.114 & 2016 & 0.09 \\
\hline 2011 & 0.109 & & \\
\hline
\end{tabular}

\section{Results}

From the model estimation results in Table II, the urbanization factor variables of OPM(the ordinary panel model)have not passed the significance test; all the variables of RNSLFM(the spatial lag fixed model based on the railway network ) and EDSLFM (the spatial lag fixed model based on the economic distance) passed 10\% significant level test; the industrial structure variable of EDSLFM (3) based on economic distance did not pass the significant level test, while all variables of RNSLFM(3) passed the $10 \%$ significant level. The test shows that the spatial lag fixed effect model based on the railway network performs well and meets the expectations of economics. The model design is more reasonable. This shows that the railway network of the Beijing-Shanghai high-speed rail economic zone has a significant spatial spillover effect on regional economic growth during the two research periods 2006-2016 and 2011-2016.

Examining the spatial spillover effect of the railway network, we can see from the RNSLFM (1) that the value of the spatial regression coefficient of the Beijing-Shanghai high-speed rail economic zone is 0.418 and passes the $1 \%$ significant level test, which indicates that in 2006-2016, the railway network of the Beijing-Shanghai high-speed rail economic zone impacts the economic ties of regional cities and above the prefecture level. There is a significant positive spatial spillover effect among the regions. During this period, the spatial spillover effect of the Beijing-Shanghai high-speed rail economic zone based on the railway network not only effectively promotes the economic development of the region, but also has a significantly positive impact on the economic growth of neighboring regions. Comparing the model estimation results in different periods in Table 4 during the period of 2006-2010, before the opening of the high-speed rail, the consumption factors and urbanization factors of RNSLFM (2) did not pass the significant test. After the opening of the high-speed rail, all variables RNSLFM (3) of the railway network passed the $10 \%$ significant level test and the spatial regression coefficient was 0.472 , which was larger than the spatial regression coefficient between 2006-2016 indicating that the goodness of fit of the effect model based on the spatial lag fixed performs well and the spatial spillover effect of the railway network after the opening of the high-speed rail is significant which promotes the regional economic development of 
Beijing-Shanghai high-speed rail economic zone and meet the expectations of economics. After nearly 10 years of development and improvement, especially the opening of the Beijing-Shanghai high-speed railway at the end of 2011, the railway network of the Beijing-Shanghai high-speed rail economic zone has not only effectively promoted the economic development along the Beijing-Shanghai high-speed rail economic zone but also the economic development of neighboring regions through the space spillover effect. The construction and operation of the Beijing-Shanghai high-speed railway will gradually connect the Beijing-Tianjin-Hebei urban agglomeration and the related cities of the Yangtze River Delta urban agglomeration to the Beijing-Shanghai high-speed rail economic zone and will follow the construction of the high-speed rail lines such as Jiaoji rail lines and Shanghai-Hangzhou-Kunming high-speed rail lines. The economic zone is closely integrated with the surrounding areas such as the Shandong Peninsula City Cluster and the Wangiiang River City Belt, gradually forming the Beijing-Shanghai high-speed rail economic zone, accelerating the flow of various production factors among the Beijing-Shanghai high-speed rail economic zone and promoting the Beijing-Shanghai high-speed rail. Economic growth in the economic zone has strengthened the spatial integration of Beijing-Shanghai high-speed rail economic zone.

Table 2. The Spatial Effect of Beijing-Shanghai HSR Economic Zone (2006-2016).

\begin{tabular}{cccc}
\hline & OPM (1) & RNSLFM (1) & EDSLFM (1) \\
\hline W & & $0.418^{* * *}$ & $0.408^{* * *}$ \\
& & $(10.57)$ & $(13.517)$ \\
\hline LAB & $-0.023 * * *$ & $-0.038^{* * *}$ & $-0.04 * * *$ \\
& $(-1.307)$ & $(-3.416)$ & $(-3.641)$ \\
\hline INV & $0.196^{* * *}$ & $0.136 * * *$ & $0.136^{* * *}$ \\
& $(11.220)$ & $(8.315)$ & $(8.575)$ \\
\hline SC & $0.397 * * *$ & $0.2 * * *$ & $0.219^{* * *}$ \\
& $(16.131)$ & $(7.076)$ & $(8.306)$ \\
\hline HL & $-0.106 * * *$ & $-0.101 * * *$ & $-0.107 * * *$ \\
& $(-6.049)$ & $(-6.617)$ & $(-7.106)$ \\
\hline UR & -0.066 & $-0.027 *$ & $-0.026 *$ \\
& $(-1.348)$ & $(-1.752)$ & $(-1.722)$ \\
\hline FE & $0.185^{* * *}$ & $0.126 * * *$ & $0.137 * * *$ \\
& $(11.353)$ & $(8.297)$ & $(9.251)$ \\
\hline Sample & 660 & 660 & 660 \\
\hline
\end{tabular}

According to the model measurement results, labor force variable and urbanization variable have a significant negative impact on the economic growth of Beijing-Shanghai high-speed railway economic zone. On the one hand, the development of urbanization does not match the economic development of Beijing-Shanghai high-speed railway economic zone. The economic development speed of Beijing-Shanghai high-speed railway economic zone is much higher than the development speed of urbanization. The GDP of Beijing-Shanghai high-speed railway economic zone in 2006 and 2016 is RMB 8,479.791 billion and RMB 27,101.580 billion respectively. The GDP in 2016 is 3.196 times as much as that in 2006 and 1.75 times as much as that in 2010. The growth rate of GDP is $219.6 \%$ during 2006-2016, while the urbanization rate of the economic zone has increased from $44.72 \%$ in 2006 to $58.2 \%$ in 2016 , with a growth rate of about $30.14 \%$. Moreover the urbanization rate of the economic zone in 2016 is just higher than the national urbanization rate which is $57.4 \%$. In 2016, the number of cities in the economic zone whose urbanization rate is lower than national rate is 28. And 11cities have no access to high speed railway, accounting for $57.89 \%$. The average urbanization rate of cities with high speed railway in the economic zone has reached about $62.05 \%$, and the average urbanization rate of cities without high speed railway is $54.75 \%$. The opening of Beijing-Shanghai high speed railway has accelerated the urbanization process of the economic zone to some extent. On the other hand, the development of labor force in the economic zone of Beijing-Shanghai high-speed railway doesn't match with the economic development, but also is influenced by the change of industrial structure. The number of employment in the economic zone has 
increased from RMB 203.0806 million in 2006 to 234.7926 million in 2016. The number of employment has increased by 31.712 million, and the employment growth rate is about $15.62 \%$ during the period of 2006-2016. The change of employment figures in the economic zone is also reflected on the industrial structure change of employment number. The employment number of all three industries in the economic zone in 2006 was 71.11451 million, 63.5405 million and 68.395 million, and each proportion was $35.03 \%, 31.29 \%$ and $33.68 \%$. The employment number of all three industries in the economic zone in 2016 was 57.009 million, 80.3237 million and 97.4599 million, and each proportion was $24.28 \%, 34.21 \%$ and $41.51 \%$. The number of employment in the primary industry of the economic zone is gradually declining, while the number of employment in the secondary and tertiary industries is gradually rising. The growth rate of the tertiary industry is higher than that of the secondary industry. The opening of the Beijing-Shanghai high-speed railway has reduced the transportation cost of the labor mobility, and promoted the adjustment of the employment structure in the economic zone. The factor of China's unique labor resources cannot be ignored as it contributes to the economic growth.

Table 3. The Spatial Effect of Beijing-Shanghai HSR Economic Zone (2006-2010).

\begin{tabular}{llll}
\hline & \multicolumn{1}{c}{ OPM (2) } & \multicolumn{1}{c}{ RNSLFM (2) } & \multicolumn{1}{c}{ EDSLFM (2) } \\
\hline W & & $0.662 * * *$ & $0.494 * * *$ \\
& & $(13.736)$ & $(10.622)$ \\
\hline LAB & $-0.036^{* *}$ & -0.005 & -0.013 \\
& $(-2.478)$ & $(-0.5)$ & $(-1.228)$ \\
\hline INV & $0.187 * * *$ & $0.057 * * *$ & $0.0962 * * *$ \\
& $(6.828)$ & $(2.627)$ & $(4.312)$ \\
\hline SC & $0.222^{* * *}$ & 0.037 & $0.077 * * *$ \\
& $(6.649)$ & $(1.395)$ & $(2.755)$ \\
\hline HL & -0.019 & $-0.039 * *$ & $-0.410^{* *}$ \\
& $(-0.718)$ & $(-2.117)$ & $(-2.111)$ \\
\hline UR & -0.005 & 0.003 & -0.0004 \\
& $(-0.220)$ & $(0.219)$ & $(-0.0256)$ \\
\hline FE & $0.303 * * *$ & $0.136 * * *$ & $0.181 * *$ \\
& $(9.669)$ & $(5.619)$ & $(7.226)$ \\
\hline Sample & 300 & 300 & 300 \\
\hline
\end{tabular}

The optimizing and upgrading of the economic structure is the core content of the sustainable and stable growth of the regional economy in the economic zone of Beijing-Shanghai high-speed railway. Analyzing the measurement results from industrial structure, the results of the model measurement show that the advanced factors of industrial structure have caused a significant negative effect on the regional economic growth of the Beijing-Shanghai high-speed railway economic zone in the periods of 2006-2016 and 2011-2016. The proportion of GDP in secondary industry and in tertiary industry has changed since the industrial structure optimization and upgrading of Beijing-Shanghai high-speed railway economic zone during the period of 2006-2016. The GDP ratio of the secondary industry of the economic zone in 2006, 2010 and 2016 was $51.56 \%, 49.44 \%$ and 42\%; the GDP ratio of the tertiary industry of the economic zone in 2006, 2010 and 2016 was $41.70 \%, 44.16 \%$ and 52.50\%. In 2006, 2010 and 2016, the secondary industry GDP ratio in cities with high speed railway of the economic zone was $51.18 \%, 48.89 \%$ and $41.07 \%$; in the same period, the GDP ratio of the tertiary industries in these cities was $43.60 \%, 45.91 \%$ and $54.39 \%$. Thus, in the period of 2006-2016, the secondary industry GDP ratio of the economic zone accounted for a certain downward trend by decreasing $9.56 \%$; the tertiary industry GDP ratio accounted for a certain upward trend by increasing $10.80 \%$. In the same period, the secondary industry GDP ratio in cities of the economic zone decreased by $10.11 \%$; and the proportion of GDP in the tertiary industry rose by $10.79 \%$. This shows that the industry in the economic zone has a process of upgrading from the secondary industry to the tertiary industry, and the optimizing and upgrading process of the industrial structure of the economic zone has been accelerated by the opening of Beijing-Shanghai high-speed railway. The construction of high-speed railway needs raw materials, manpower and material resources, so the economy of 
mining, manufacturing, construction and other related industries will grow rapidly. After the opening of the high speed railway, it brings opportunities for urban transportation, tourism, real estate, social services and other industries with its efficient and convenient advantages, thus promoting the development of the tertiary industry in the cities along the railway. The area along the Beijing-Shanghai high-speed railway economic zone has begun to coordinate the industrial structure and factor endowment structure by the corridor effect of the high-speed railway network, and promote the adjustment of the industrial structure of the urban agglomeration in the region, and have achieved remarkable results in the optimization and upgrading of the industrial structure. The economic zone of Beijing-Shanghai high-speed railway shows the optimization and upgrading trend from economic growth which is mainly based on the growth of secondary industry to coordinating development of secondary and tertiary industrial structure.

Table 4. The Spatial Effect of Beijing-Shanghai HSR Economic Zone (2011-2016).

\begin{tabular}{|c|c|c|c|}
\hline & OPM (3) & RNSLFM (3) & EDSLFM (3) \\
\hline $\mathrm{W}$ & & $\begin{array}{c}0.472 * * * \\
(8.070)\end{array}$ & $\begin{array}{c}0.371 * * * \\
(7.464)\end{array}$ \\
\hline LAB & $\begin{array}{c}-0.057 * * * \\
(-3.673)\end{array}$ & $\begin{array}{l}-0.057 * * \\
(-4.412)\end{array}$ & $\begin{array}{c}-0.058 * * * \\
(-4.479)\end{array}$ \\
\hline INV & $\begin{array}{l}0.317 * * * \\
(10.205)\end{array}$ & $\begin{array}{c}0.234 * * * \\
(8.227)\end{array}$ & $\begin{array}{c}0.245^{* * * *} \\
(8.623)\end{array}$ \\
\hline $\mathrm{SC}$ & $\begin{array}{c}0.245 * * * \\
(6.824)\end{array}$ & $\begin{array}{c}0.104 * * * \\
(3.034)\end{array}$ & $\begin{array}{c}0.138 * * * \\
(4.224)\end{array}$ \\
\hline $\mathrm{HL}$ & $\begin{array}{c}-0.015 \\
(-0.696)\end{array}$ & $\begin{array}{l}-0.031 * \\
(-1.679)\end{array}$ & $\begin{array}{c}-0.030 \\
(-1.642)\end{array}$ \\
\hline UR & $\begin{array}{l}-0.027 \\
(-0.88)\end{array}$ & $\begin{array}{c}-0.098 * * * \\
(-3.698)\end{array}$ & $\begin{array}{c}-0.077 * * * \\
(-2.925)\end{array}$ \\
\hline $\mathrm{FE}$ & $\begin{array}{c}0.041 * * * \\
(2.961)\end{array}$ & $\begin{array}{l}0.027 * * \\
(2.288)\end{array}$ & $\begin{array}{c}0.033 * * * \\
(2.759)\end{array}$ \\
\hline Sample & 360 & 360 & 360 \\
\hline
\end{tabular}

\section{Conclusions}

The major findings of this study are summarized as follows:

HSR has a significantly positive effect on local economic growth of the Beijing-Shanghai high-speed rail economic zone. During this period, the spatial spillover effect of the Beijing-Shanghai high-speed rail economic zone based on the railway network not only effectively promotes the economic development of the region, but also has a significantly positive impact on the economic growth of neighboring regions. The railway network of the Beijing-Shanghai high-speed rail economic zone has not only effectively promoted the economic development along the Beijing-Shanghai high-speed rail economic zone but also the economic development of neighboring regions through the space spillover effect.

Different economic factors have different influence on regional economic growth activities under the influence of railway network. Its investment and consumption activities have promoted economic growth in the surrounding areas under the influence of high-speed railways. Labor force variable and urbanization variable have a significant negative impact on the economic growth of Beijing-Shanghai high-speed railway economic zone. The development of urbanization does not match the economic development of Beijing-Shanghai high-speed railway economic zone. The development of labor force in the economic zone of Beijing-Shanghai high-speed railway doesn't match with the economic development, but also is influenced by the change of industrial structure. The industry in the economic zone has a process of upgrading from the secondary industry to the tertiary industry, and the optimizing and upgrading process of the industrial structure of the economic zone has been accelerated by the opening of Beijing-Shanghai high-speed railway. The economic zone of Beijing-Shanghai high-speed railway shows the optimization and upgrading trend from economic growth which is mainly based on the growth of secondary industry to coordinating development of 
secondary and tertiary industrial structure. The contribution of the Government finance expenditure factor on the local economic growth cannot be ignored.

\section{Acknowledgement}

This research was financially supported by the National Natural Science Foundation of China (Grant NO. 51778047).

\section{References}

[1] N. N. Zhang, Y. L. Xu, Research on the impacts of high speed rail on regional development, Areal Research and Development, Vol.24, No.3, pp. 32-36, 2005.

[2] F. B. Lai, C. M. Liu, C. H. Rong, The effect of high-speed railway on regional economic development and empirical test, Dongyue Tribune, Vol.37, No.6, pp. 120-127, 2016.

[3] H. X. Jiang, X. C. Meng, Impact of High Speed Rail upon Market Potential of Urban Industries in China, Modern Urban Research, No.11, pp. 108-114, 2017.

[4] S. M. Jia, C. L. Qin, The Influence of High-speed Railway to the Equilibrium of China's Regional Economic Patten, Areal Research and Development, Vol.34, No.2, pp. 13-20, 2015

[5] Y. Chen, X. C. Meng, The Impact of High-speed Railway on Passenger Transport Market, Regional Economy and Spatial Structure, Urban Development Studies, Vol.20, No.4, pp. 119-124, 2013.

[6] J. I. Mozano, Measuring the substitution effects between High Speed Rail and air transport in Spain, Journal of Transport Geography, Vol.43, No.2, pp. 59-65, 2015

[7] J. E. Wang, J. X. Ding, High-speed Rail and Its impacts on the Urban Spatial Structure of China, Urban Planning International, Vol.26, No.6, pp. 49-54, 2011.

[8] Y. Zhao, X. M. Li, G. D. Wei, The Influence Evaluation Model of High-speed Railway Station Based on the Accessibility, Areal Research and Development, Vol.34, No.3, pp. 12-16, 2015.

[9] H. X. Jiang, H. Y. Cai, X. C. Meng, "The structural impact of high speed rail upon urban industries in China, Human Geography, Vol.32, No.5, pp. 132-138, 2017.

[10]X. L. Zhang, Has Transport Infrastructure Promoted Regional Economic Growth? With an Analysis of the Spatial Spillover Effects of Transport Infrastructure, Social Sciences in China, No.3 pp. 60-77+206, 2012. 